\title{
1,25-dihydroxyvitamin-D3 but not the clinically applied marker 25-hydroxyvitamin-D3 predicts survival after stem cell transplantation
}

\author{
Katrin Peter $\mathbb{D}^{1} \cdot$ Peter J. Siska $\mathbb{D}^{1} \cdot{\text { Tobias Roider }(\mathbb{D})^{1,5} \cdot \text { Carina Matos }^{1} \cdot \text { Heiko Bruns }}^{2} \cdot$ Kathrin Renner $^{1}$.

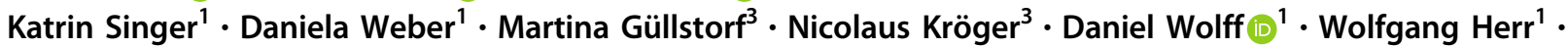 \\ Francis Ayuk ${ }^{3} \cdot$ Ernst Holler $^{1} \cdot$ Klaus Stark $^{4} \cdot$ Iris M. Heid ${ }^{4} \cdot$ Marina Kreutz $\mathbb{D}^{1}$
}

Received: 14 April 2020 / Revised: 25 July 2020 / Accepted: 6 August 2020 / Published online: 27 August 2020

(c) The Author(s) 2020. This article is published with open access

\begin{abstract}
The serum level of 25-hydroxyvitamin-D3 is accepted as marker for a person's vitamin D status but its role for the outcome of allogeneic hematopoietic stem cell transplantation (HSCT) is controversially discussed. The impact of 1,25-dihydroxyvitaminD3 on HSCT outcome, however, has never been studied. In a discovery cohort of 143 HSCT patients we repeatedly (day -16 to 100) measured 1,25-dihydroxyvitamin-D3 and in comparison the well-established marker for serum vitamin D status 25hydroxyvitamin-D3. Only lower 1,25-dihydroxyvitamin-D3 levels around HSCT (day -2 to 7, peritransplant) were significantly associated with higher 1-year treatment-related mortality (TRM) risk (Mann-Whitney $\mathrm{U}$ test, $P=0.001$ ). This was confirmed by Cox-model regression without and with adjustment for baseline risk factors and severe acute Graft-versus-Host disease (aGvHD; unadjusted $P=0.001$, adjusted $P=0.005$ ). The optimal threshold for 1,25-dihydroxyvitamin-D3 to identify patients at high risk was $139.5 \mathrm{pM}$. Also in three replication cohorts consisting of altogether 365 patients 1,25-dihydroxyvitamin-D3 levels below $139.5 \mathrm{pM}$ had a 3.3-fold increased risk of TRM independent of severe aGvHD compared to patients above $139.5 \mathrm{pM}$ (Cox-model unadjusted $P<0.0005$, adjusted $P=0.001$ ). Our data highlight peritransplant 1,25-dihydroxyvitamin-D3 levels but not the commonly monitored 25-hydroxyvitamin-D3 levels as potent predictor of 1-year TRM and suggest to monitor both vitamin D metabolites in HSCT patients.
\end{abstract}

These authors contributed equally: Iris M. Heid, Marina Kreutz

Supplementary information The online version of this article (https:// doi.org/10.1038/s41409-020-01031-w) contains supplementary material, which is available to authorized users.

Katrin Peter

katrin.1.peter@gmail.com

$\triangle$ Marina Kreutz

marina.kreutz@ukr.de

1 Department of Internal Medicine III, Hematology and Medical Oncology, University Medical Center of Regensburg, Regensburg, Germany

2 Department of Internal Medicine 5-Hematology/Oncology, University Hospital of Erlangen, Erlangen, Germany

3 Department of Stem Cell Transplantation, University Medical Center Hamburg-Eppendorf, Hamburg, Germany

4 Department for Genetic Epidemiology, University of Regensburg, Regensburg, Germany

5 Present address: Department of Medicine V, University of Heidelberg, Heidelberg, Germany

\section{Introduction}

Although treatment-related mortality (TRM) was substantially reduced among patients undergoing allogeneic hematopoietic stem cell transplantation (HSCT) over the past decade [1], the risk for TRM still remains high. Up to now, it is not possible to individually predict TRM at time of transplantation independent of known pretransplant variables as disease-associated risk factors, donor relationship, and comorbidity. An issue of debate is vitamin D3. In some studies, the impact of 25-hydroxyvitamin-D3 serum levels on adverse events of allogeneic HSCT was evaluated, but results are inconsistent [2-6]. In one prospective trial, safety and efficacy of vitamin D3 supplementation after HSCT was evaluated and no significant impact on overall survival was found [7].

25-hydroxyvitamin-D3 is a precursor of the active metabolite 1,25-dihydroxyvitamin-D3. The conversion of 25-hydroxyvitamin-D3 to 1,25-dihydroxyvitamin-D3 is mainly performed by the kidney, but also by immune cells 
[8, 9]. Little is known about the role of 1,25-dihydroxyvitamin-D3 levels with regard to HSCT and aGvHD. In rat bone marrow transplantation, an analog of 1,25-dihydroxyvitamin D3, has been shown to prevent aGvHD [10]. In humans, polymorphisms of the vitamin D receptor, mediating the biological activity of 1,25-dihydroxyvitamin-D3, were shown to correlate with survival and aGvHD in HLAmatched sibling allogeneic HSCT [11]. Recently, CarrilloCruz et al. reported a reduced incidence of cGvHD in response to vitamin D supplementation of patients with a certain VDR genotype [12].

We thus set out to investigate the role of 1,25dihydroxyvitamin-D3 and for comparison also 25hydroxyvitamin-D3 levels measured repeatedly shortly before and during the first 100 days after HSCT on 1-year TRM in a discovery cohort of 143 patients. We then tested our findings in overall 365 patients from three different cohorts in order to replicate our findings in independent data and to generalize it for different clinical settings.

\section{Materials and methods}

\section{Patient recruitment and eligibility criteria for the discovery cohort}

Our discovery cohort consisted of patients eligible for matched unrelated or matched related HSCT at the Regensburg University Medical Center with HSCT between May 2012 and February 2015. Excluded from HSCT were patients with poor performance status (Karnofsky grade $<$ 80, corresponding to $E C O G \geq 2$ ), progressive underlying disease, pregnancy or breast-feeding, moderate or severe cardiac insufficiency, moderate or severe renal insufficiency (serum creatinine levels $>2 \mathrm{mg} / \mathrm{dl}$ ), high age ( $>70$ years), uncontrolled acute or chronic infection or patients with liver failure (serum bilirubin $>2 \mathrm{mg} / \mathrm{dl}$, levels of alanine aminotransferase (ALT), or aspartate aminotransferase (AST)) $\leq$ $2 \mathrm{x}$ upper normal level). From the cohort of 172 patients that underwent HSCT in the noted time period, 13 patients with repeated HSCT were excluded obtaining a cohort of 159 patients.

\section{Transplantation and concomitant therapy for patients in the discovery cohort}

Patients were admitted to hospital 6-16 days before HSCT. Conditioning regimens included chemotherapy with or without irradiation and started between 6 and 8 days prior to HSCT. Bone marrow or peripheral-blood mononuclear cells were not T-cell-depleted or cryopreserved before HSCT. For aGvHD prophylaxis, patients received one of two immunosuppressive regimens: cyclosporine and methotrexate, or cyclosporine and mycophenolate. In case of cyclosporine-associated toxicity, the latter was replaced by tacrolimus. Prior to HSCT (days -3 to -1 ), additional immunosuppressive prophylaxis with rabbit antithymocyte globulin (ATG, Grafalon) was administered in patients receiving grafts from matched unrelated donors. Initial aGVHD treatment consisted of prednisolone $1-2 \mathrm{mg} / \mathrm{kg} /$ day with budesonide added in the presence of gastrointestinal symptoms. For gastrointestinal decontamination, all patients received prophylactic rifaximin ( $200 \mathrm{mg}$ twice a day) from start of conditioning until engraftment (absolute neutrophil count $>500 / \mu \mathrm{L}$ ). Upon signs of infection before and after HSCT, patients were treated with systemic broad spectrum antibiotics. For routine antifungal prophylaxis, patients received fluconazole or posaconazole, for pneumocystispneumonia prophylaxis, patients received cotrimoxazole. Upon signs of fungal infection, patients were treated with systemic mold active antifungal agents. Following HSCT, patients were monitored in the transplant unit and discharged after 28 days if clinically possible and subsequently regularly monitored in an outpatient setting.

\section{Vitamin D supplementation and serum measurements in the patients of the discovery cohort}

All HSCT recipients in the discovery cohort received oral high-dose vitamin D3 supplementation (Vigantol oil, $20.000 \mathrm{IU} / \mathrm{ml}$, Merck) consisting of a $50.000 \mathrm{IU}-$ dose upon admission to hospital (d-16 to d-6) followed by daily administration of 10.000 IU. To monitor 25hydroxyvitamin-D3 and 1,25-dihydroxyvitamin-D3 serum levels, blood was drawn repeatedly during inpatient stay and thereafter during routine outpatient visits. To avoid hypercalcemia, serum calcium levels were assessed twice a week. The described supplementation dose was maintained until patients reached 25-hydroxyvitamin-D3 serum levels of $150-200 \mathrm{nmol} / \mathrm{L}$ with subsequent dose adjustment to avoid 25-hydroxyvitamin-D3 levels >150-200 nmol/L. Vitamin D levels were analyzed immediately or from sera stored at $-80^{\circ} \mathrm{C}$ by the Department of Clinical Chemistry, University Medical Center of Regensburg. From May 2012 to October 2014, 25-hydroxyvitamin-D3 serum levels were determined by means of chemiluminescence immunoassay according to the manufacturer's instructions (Immunodiagnostic systems, Frankfurt am Main, Germany). After validation for comparability, from November 2014 on, 25-hydroxyvitamin-D3 serum levels were analyzed by means of liquid chromatography high-resolution tandem mass spectrometry as described elsewhere [13]. 1,25-dihydroxyvitamin-D3 concentrations were measured using a radioimmunoassay according to the manufacturer's instructions (Immunodiagnostic systems, Frankfurt am 
Main, Germany) by the Department of Clinical Chemistry, University Medical Center of Regensburg.

\section{Analyzed data for the discovery cohort}

All of the 159 patients with full information on age, sex, donor type, survival, and available peritransplant 1,25-dihydroxyvitamin-D3 and 25-hydroxyvitamin-D3 levels were included into the analysis of the discovery cohort. Due to these criteria, further 16 patients with missing information about vitamin D serum levels at the day of HSCT were excluded obtaining a discovery cohort of 143 patients. Our primary endpoint was TRM within 1 year, defined as death due to any cause (aGvHD, infection, bleeding and organ failure) in the absence of relapse. Competing risk of death was defined as death due to relapse of the underlying malignancy. Overall mortality was defined as any death (TRM or relapse) within the first year. Mortality after the first year was not incorporated into our analysis. Our secondary endpoint was severe aGvHD, defined as aGvHD grade 3-4, within the first year according to clinical criteria [14].

For the analysis, serum 1,25-dihydroxyvitamin-D3 and 25hydroxyvitamin-D3 values were categorized according to the time of blood sampling: at hospital admission (day -16 to -6 , baseline), around HSCT (day -2 to 7 , peritransplant), early follow-up around day 14 (day 11 to 17), day 21 (day 18 to 24), day 28 (day 25 to 31), and late follow-up (day 32 to 100). Missing baseline levels for 1,25-dihydroxyvitamin-D3 or 25-hydroxyvitamin-D3 were observed for 16 or 19 , respectively, out of 143 patients; these were imputed by the median of existing 1,25-dihydroxyvitamin-D3 or 25hydroxyvitamin-D3 baseline levels (82 pM or $43.5 \mathrm{nM}$, respectively). In the discovery cohort, median levels of 1,25dihydroxyvitamin-D3 and 25-hydroxyvitamin-D3 at baseline were $172.0 \mathrm{pM}$ and $54.0 \mathrm{nM}$, respectively. At the time of HSCT (day -2 to 7), at least one serum value for 1,25 dihydroxyvitamin-D3 and for 25-hydroxyvitamin-D3 was available for each patient due to our inclusion criteria. If multiple serum values within baseline, peritransplant or early follow-up intervals (until day 31 ) were available, the measurement closest to day $-10,0,14,21$, or 28 , respectively, was used. For the late follow-up (day 32 to 100), the median of the available 1,25-dihydroxyvitamin-D3 or 25hydroxyvitamin-D3 serum levels, respectively, was used.

\section{Association analysis in discovery data}

To avoid any model assumptions in our first analysis of the discovery data, the Mann-Whitney $U$ test was applied to test 1,25-dihydroxyvitamin-D3 and 25-hydroxyvitamin-D3 levels at each time interval for differences between patients experiencing TRM compared to those who did not. We selected the metabolite and time intervals with statistically significant association with TRM (Bonferroni-corrected significance level at $0.05 /(6 \times 2)=0.004)$.

For the selected metabolite and the time interval, we evaluated the association with time-to-death further and derived hazard ratio (HR) estimates using Cox proportional hazards models unadjusted and adjusted for risk factors (age, donor type, tumor stage prior to HSCT, intensity of the conditioning regime, severe aGvHD).

A Kaplan-Meier curve was generated to visualize 1-year-survival comparing patients with above versus below median serum vitamin D3 levels in the selected time intervals. The log rank test and an unadjusted Cox-model were used to test for difference in survival for patients with above versus below median serum levels. A receiveroperating-characteristic (ROC) curve and the optimal threshold for 1,25-dihydroxyvitamin-D3 serum levels for a best prediction of 1-year TRM were computed using the Youden Index [15]. All data analyses were performed using SPSS Statistics version 23 (IBM, Armonk, USA).

\section{Replication cohorts}

Our replication stage consisted of three patient cohorts from various clinical settings to replicate our initial findings and to generalize for other clinical settings: (I) HSCT patients from Regensburg transplanted between March 2015 and May 2017 receiving the same high-dose vitamin D3 supplementation as the discovery cohort, (II) HSCT patients from Regensburg transplanted between March 2011 and February 2013 receiving vitamin D3 supplementation at lower dose (ranging from 1000 to $5000 \mathrm{IU} / \mathrm{d}$, Vigantoletten, $1000 \mathrm{IU} / \mathrm{tablet}$, Merck), (III) HSCT patients from the University Medical Center Hamburg-Eppendorf transplanted between February 2012 and August 2014 receiving no vitamin D3 supplementation. Eligibility and exclusion criteria for all three replication groups were the same as in the discovery cohort. We excluded 26 patients with unavailable serum aliquots from blood drawn at the relevant time interval, yielding $n=115, n=107$ and $n=143$ patients in replication cohort I, II, and III, respectively.

In replication cohort I, concomitant therapy was the same as in the discovery cohort. For replication cohorts II and III, the concomitant therapy differed: in replication cohort II, the concomitant therapy was comparable to the discovery cohort with the exception of the administration of prophylactic Ciprofloxacin $(500 \mathrm{mg}$ twice a day) and Metronidazole (400 mg thrice a day) for gastrointestinal decontamination from start of conditioning until engraftment. Ciprofloxacin (500 mg twice a day) and Metronidazole $(400 \mathrm{mg}$ thrice a day) for gastrointestinal decontamination were also administered to 85 out of 143 patients in replication cohort III from start of conditioning until engraftment. In replication cohort III, ATG was administered to almost all patients independent 
of the source of transplanted cells $(n=117$ rabbit ATG, Grafalon; $n=17$ rabbit ATG, Merieux; $n=9$ no ATG). Furthermore, initial aGvHD was treated systemically with Methyl-Prednisolone or Dexamethason and topically with topical steroids.

In all three replication cohorts, serum was stored at $-80{ }^{\circ} \mathrm{C}$ and the serum obtained in the relevant time interval was transferred to Regensburg for central measurement. 25-hydroxyvitamin-D3 serum levels were analyzed as mentioned above. 1,25-dihydroxyvitamin-D3 levels were analyzed by the MVZ Laborzentrum Ettlingen, Germany, using the same method as described above.

\section{Association analysis in the replication stage}

We utilized the optimal cutoff for vitamin D levels derived in the discovery data to define two groups of patients in the replication data: patients below and above the cutoff. We visualized survival in these two groups by Kaplan-Meier curves in each of the three cohorts and in the joint replication data.

We tested these dichotomized vitamin D levels for association with TRM in the joint replication data with the unadjusted Cox-model. We also applied a Cox-model unadjusted and adjusted for risk factors (age, donor type, tumor stage prior to HSCT, intensity of the conditioning regime, severe aGvHD). For this, we derived estimates for each covariate in the model separately by replication cohort and derived joint estimates across the three replication cohorts by a fixed-effect inverse-variance meta-analysis, for each covariate in the model. This joint estimate is an estimate of the underlying true effect, when all cohorts have the same effect, and it can be interpreted as the average of underlying effects, when the cohorts have varying effects [16].

\section{Study approval}

The studies of the discovery cohort as well as the replication cohorts I and II were approved by the Ethics Committee of the University Medical Center of Regensburg (02/220). The study of the replication cohort III was approved by the Ethics Committee of the University Medical Center Hamburg-Eppendorf (PV4085). All subjects gave written informed consent according to internal standards and in accordance with the Declaration of Helsinki.

\section{Results}

\section{Overview on design and collected patient samples}

We adopted a two-stage design. In the discovery cohort of 143 patients (Regensburg study center, high-dose vitamin D3 supplementation), we tested 1,25-dihydroxyvitamin-D3 and 25-hydroxyvitamin-D3 levels measured at up to six time points between days -16 before HSCT up to day 100 after HSCT for their association with TRM within 1 year. Then, we selected the vitamin D metabolite and time interval showing statistical significant association with TRM for further analyses. Finally, we tested this metabolite from the selected time interval in independent replication data consisting of a total of 365 patients from three different clinic settings: (I) 115 patients from the same study center and the same setting as the discovery cohort (replication data I, Regensburg study center, highdose vitamin D3 supplementation), (II) 107 patients from the same study center with an alternative type of vitamin D3 supplementation (replication data II, Regensburg study center, moderate vitamin D3 supplementation), and (III) 143 patients from another study center (replication data III, Hamburg study center, no vitamin D3 supplementation). All patients were enrolled at baseline shortly before HSCT (day -16 to -6$)$ and followed for 365 days to record complications including severe aGvHD and survival status. Baseline patient characteristics of all 508 patients in this vitamin D3 study were similar across the four cohorts (Table 1). Median baseline vitamin D metabolite measurements across the four cohorts reflected the different approaches toward vitamin D3 supplementation (Table 2). Among the 508 patients, 89 patients experienced TRM and 70 died due to relapse or other causes (Table 2).

\section{Discovery cohort identified peritransplant 1,25- dihydroxyvitamin-D3 levels and late follow-up 25- hydroxyvitamin-D3 to predict first-year TRM}

In the discovery cohort of 143 patients, we first explored the time trend of serum levels from day -16 to day 100 after HSCT. 25-hydroxyvitamin-D3 revealed a slight, but steady increase, whereas 1,25-dihydroxyvitamin-D3 peaked around the time of HSCT (day -2 to 7, Fig. 1a, b). Further analysis was conducted with serum levels categorized into six different time intervals (Methods): (i) measurement at hospital admission (day -16 to -6 , baseline), (ii) around HSCT (day -2 to 7 , peritransplant), (iii, iv, v) early follow-up during the inpatient hospital stay with weekly samples (three intervals weekly apart: day 11 to 17 ; day 18 to 24 ; day 25 to 31 ), (vi) late follow-up with inpatient or outpatient care (days 32 to 100). Interval-specific median serum levels and number of deaths or severe aGvHD are shown in Supplemental Table S1. To identify association of serum levels with TRM, 25-hydroxyvitaminD3 and 1,25-dihydroxyvitamin-D3 serum levels for each of the six time intervals were compared between patients who experienced TRM and those that did not die or died from relapse $(n=143,23$ with TRM, Table 2, Table S1). For 
Table 1 Patient characteristics at baseline for the discovery and the three replication cohorts.

\begin{tabular}{|c|c|c|c|c|}
\hline Characteristic & $\begin{array}{l}\text { Discovery } \\
(n=143)\end{array}$ & $\begin{array}{l}\text { Replication I } \\
(n=115)\end{array}$ & $\begin{array}{l}\text { Replication II } \\
(n=107)\end{array}$ & $\begin{array}{l}\text { Replication III } \\
(n=143)\end{array}$ \\
\hline Study center & Regensburg & Regensburg & Regensburg & Hamburg \\
\hline Vitamin D3 suppl. ${ }^{\mathrm{a}}$ & High-dose & High-dose & Moderate & None \\
\hline Male sex & $84(58.7 \%)$ & $75(65.2 \%)$ & $74(69.2 \%)$ & $94(65.7 \%)$ \\
\hline median age (range)[yr] & $56(26-70)$ & $56(19-69)$ & $52(19-71)$ & $58(18-75)$ \\
\hline \multicolumn{5}{|l|}{ Diagnosis } \\
\hline Aplastic anemia & $2(1.4 \%)$ & $5(4.3 \%)$ & $2(1.9 \%)$ & $2(1.4 \%)$ \\
\hline Acute leukemia & $76(53.1 \%)$ & $62(53.9 \%)$ & $55(51.4 \%)$ & $47(32.9 \%)$ \\
\hline Morbus Hodgkin & $5(3.5 \%)$ & 0 & $1(0.9 \%)$ & 0 \\
\hline MDS & $17(11.9 \%)$ & $16(13.9 \%)$ & $12(11.2 \%)$ & $25(17.5 \%)$ \\
\hline MPN & $4(2.8 \%)$ & $12(10.4 \%)$ & $6(5.6 \%)$ & $27(18.9 \%)$ \\
\hline NHL & $34(23.8 \%)$ & $18(15.7 \%)$ & $26(24.3 \%)$ & $20(14.0 \%)$ \\
\hline PMF & $5(3.5 \%)$ & $2(1.7 \%)$ & $4(3.7 \%)$ & $22(15.4 \%)$ \\
\hline Late tumor stage $\mathrm{b}^{\mathrm{b}}$ & $75(58.6 \%)$ & $74(64.3 \%)$ & $65(60.7 \%)$ & $101(70.6 \%)$ \\
\hline Unrelated donor & $102(71.3 \%)$ & $81(70.4 \%)$ & $83(77.6 \%)$ & $108(75.5 \%)$ \\
\hline ATG before HSCT yes & $102(71.3 \%)$ & $81(70.4 \%)$ & $83(77.6 \%)$ & $134(93.7 \%)$ \\
\hline Standard conditioning ${ }^{\mathrm{c}}$ & $13(9.4 \%)$ & $20(17.4 \%)$ & $17(15.9 \%)$ & $35(24.5 \%)$ \\
\hline Steroids $\geq 1 \mathrm{mg} / \mathrm{kg}^{\mathrm{d}}$ & $65(53.3 \%)$ & $52(45.2 \%)$ & $55(51.4 \%)$ & $74(51.7 \%)$ \\
\hline Karnofsky score $<90^{\mathrm{e}}$ & $46(33.3 \%)$ & $53(46.1 \%)$ & $16(15.0 \%)$ & $94(66 \%)$ \\
\hline
\end{tabular}

Shown are characteristics of the 508 patients in the vitamin D study. Stated are number of participants and percentages, if not indicated otherwise.

suppl. supplementation, $y r$ years, $M D S$ myelodysplastic syndrome, $M P N$ myeloproliferative neoplasm, $N H L$ non-Hodgkin lymphoma, $P M F$ primary myelofibrosis, $H S C T$ hematopoietic stem cell transplantation, $A T G$ antithymocyte globulin.

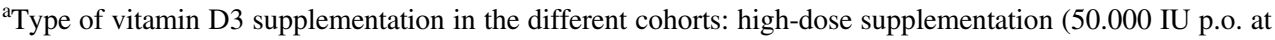
start, followed by $10.000 \mathrm{IU} / \mathrm{d}$ p.o.) was adjusted for patients with 25 -hydroxyvitamin-D3 levels higher than $200 \mathrm{nmol} / \mathrm{L}$; moderate supplementation: 1.000-5.000 IU/d p.o.

${ }^{\mathrm{b}}$ At enrollment (before HSCT), no tumor stage grading available for 15 patients from discovery and for 1 patient from replication data I, classification according to EBMT risk score [50].

${ }^{\mathrm{c}}$ Missing information on conditioning for discovery cohort from five patients.

${ }^{\mathrm{d}}$ Missing information on steroid treatment for discovery cohort, replication cohort I, and replication cohort II from 21, 5, or 7 patients, respectively.

${ }^{\mathrm{e}}$ Missing information on Karnofsky performance score for discovery cohort, replication cohort I, replication cohort II, and replication cohort III from 5, 8, 4, or 11 patients, respectively. this, we used the nonparametric Mann-Whitney $U$ test and a significance level Bonferroni-corrected for the multiple testing $(0.05 /(6 \times 2)=0.004$, two metabolites, six time intervals). Lower late follow-up 25-hydroxyvitaminD3 and lower peritransplant 1,25-dihydroxyvitaminD3 levels were statistically significantly associated with increased TRM (Fig. 1c, d; $P=0.002$ or $P=0.001$, respectively). For all other time intervals, there was no statistically significant difference of serum levels between the two groups $(P>0.004)$. We also used nonparametric Mann-Whitney $U$ to test for an association of $1,25(\mathrm{OH}) 2 \mathrm{D} 3$ serum levels and occurrence of severe aGvHD or chronic GvHD (cGvHD). However, no statistically significant association between the groups was detected (Supplemental Fig. 1).

\section{Discovery cohort substantiated peritransplant 1,25- dihydroxyvitamin-D3 levels to predict first-year TRM independent of severe aGvHD}

In order to understand the robustness of discovery cohort findings upon adjustment for other risk factors and to incorporate time-to-death, we evaluated the detected significant associations further by a Cox-regression analysis and found the following (Table 3): (i) for late follow-up 25hydoxyvitamin-D3, the significant association with TRM in the unadjusted model ( $n=88,17$ with TRM, $P=0.001$, hazard ratio $(\mathrm{HR})=0.98$ per unit increase) persisted when adjusting for age, sex, donor status, and tumor stage $(n=77$, 16 with TRM, $P=0.004, \mathrm{HR}=0.98$ ), but diminished when adding severe aGvHD into the model $(n=77,16$ with 
Table 2 Serum measurements and events during follow-up for the discovery and the three replication cohorts.

\begin{tabular}{|c|c|c|c|c|}
\hline Measurement/event & $\begin{array}{l}\text { Discovery } \\
(n=143)\end{array}$ & $\begin{array}{l}\text { Replication I } \\
(n=115)\end{array}$ & $\begin{array}{l}\text { Replication II } \\
(n=107)\end{array}$ & $\begin{array}{l}\text { Replication III } \\
(n=143)\end{array}$ \\
\hline \multicolumn{5}{|l|}{ Peritransplant $1,25(\mathrm{OH}) 2 \mathrm{D} 3^{\mathrm{a}}$} \\
\hline$n$ & 143 & 115 & 107 & 143 \\
\hline Median $[\mathrm{pM}]$ & 172.0 & 181.2 & 96.7 & 81.4 \\
\hline $\mathrm{IQR}[\mathrm{pM}]$ & $(97.0-238.0)$ & $(132.6-259.2)$ & $(62.5-161.9)$ & $(53.0-128.0)$ \\
\hline \multicolumn{5}{|l|}{ Peritransplant $25(\mathrm{OH}) \mathrm{D} 3^{\mathrm{b}}$} \\
\hline$n$ & 143 & 48 & 69 & 141 \\
\hline Median $[\mathrm{nM}]$ & 54.0 & 47.0 & 36.0 & 22.3 \\
\hline $\mathrm{IQR}[\mathrm{nM}]$ & $(42.0-67.0)$ & $(38.3-64.0)$ & $(29.0-49.7)$ & $(14.8-38.2)$ \\
\hline \multicolumn{5}{|l|}{ Mortality $^{\mathrm{c}}$} \\
\hline TRM & $23(16.1 \%)$ & $17(14.8 \%)$ & $24(22.4 \%)$ & $25(17.5 \%)$ \\
\hline Death due to relapse & $17(11.9 \%)$ & $11(9.6 \%)$ & $21(19.6 \%)$ & $37(25.9 \%)$ \\
\hline Death, other causes & 0 & 0 & 0 & 1 \\
\hline Lost-to-follow-up & 0 & 0 & 0 & 0 \\
\hline None (alive after 1 yr) & $109(76.2 \%)$ & $89(77.4 \%)$ & $72(67.3 \%)$ & $92(64.3 \%)$ \\
\hline \#Severe $\mathrm{aGvHD}^{\mathrm{d}}$ & $21(14.7 \%)$ & $9(7.8 \%)$ & $16(15.0 \%)$ & $18(12.6 \%)$ \\
\hline $\begin{array}{l}\text { Median time to TRM }{ }^{\mathrm{c}}[\mathrm{d} \\
\text { after HSCT] (range) }\end{array}$ & $163(19-360)$ & $165(50-342)$ & $118(2-301)$ & $113(17-320)$ \\
\hline IQR [d after HSCT] & 89-342 & $57-242$ & $43-192$ & $56-198$ \\
\hline $\begin{array}{l}\text { Median time to max. severe } \\
\text { aGvHD [d after HSCT] } \\
\text { (range) }\end{array}$ & $70(14-354)$ & $42(27-220)$ & $84(17-275)$ & $120(5-331)$ \\
\hline IQR [d after HSCT] & $53-135$ & $33-150$ & $33-163$ & $49-175$ \\
\hline
\end{tabular}

Shown are median vitamin D3 levels of the 508 patients in the vitamin D study and the number of deaths and other events occurring during follow-up. Stated are number of patients and percentages, if not indicated otherwise.

1,25( $\mathrm{OH}) 2 \mathrm{D} 3$ 1,25-dihydroxyvitamin-D3, 25( $\mathrm{OH}) \mathrm{D} 3$ 25-hydroxyvitamin-D3, IQR interquartile range, TRM treatment-related mortality, $a G v H D$ acute Graft-versus-Host disease, HSCT hematopoietic stem cell transplantation.

${ }^{\mathrm{a}}$ 1,25-dihydroxyvitamin-D3 level at time of HSCT (days -2 to 7).

b25-hydroxyvitamin-D3 level at time of HSCT (days -2 to 7).

${ }^{\mathrm{c}}$ Death in first year after HSCT.

${ }^{\mathrm{d}}$ Any occurrence of aGvHD 3-4 [14] during first year after HSCT; for replication cohort II from three patients evaluation of aGvHD grade not possible due to death early after HSCT or graft failure.
TRM, $P=0.069$, HR $=0.99$ ). (ii) For peritransplant 1,25 dihydroxyvitamin-D3, the significant association with TRM observed in the unadjusted model $(n=143,23$ with TRM, $P=0.001, \quad H R=0.99)$ persisted also after accounting for severe $\mathrm{aGvHD}(n=128,21$ with TRM, $P=0.005$, $\mathrm{HR}=0.99$ ). This association of 1,25-dihydroxyvitaminD3 with TRM was also independent of peritransplant 25hydroxyvitamin-D3 levels $(n=128,21$ with TRM, $P=$ 0.005 , HR $=0.99$ ). In summary, we selected the peritransplant 1,25-dihydroxyvitamin-D3 levels as the predominantly interesting, since this association was independent of severe aGvHD and measured around the time of transplantation, while the late 25-hydroxyvitamin-D3 levels appeared to be observed together with the occurrence of severe aGvHD (median time to maximum severe aGvHD across all patients day 70 , interquartile range 53-135 days, Table 2).

\section{Clinical relevance and optimal threshold for 1,25- dihydroxyvitamin-D3 to predict 1-year TRM}

We visualized the differential survival between patients with high versus low peritransplant 1,25-dihydroxyvitamin-D3 levels (dichotomized at the median $172 \mathrm{pM}$, Fig. 2a) by Kaplan-Meier curves. We found a statistical significant association of the dichotomized 1,25-dihydroxyvitamin-D3 levels with time-to-death (median time-to-death $=151$ days vs. 275 days in the group $\leq 172 \mathrm{pM}$ vs. $>172 \mathrm{pM}$, respectively; $\log$ rank test $P=0.009$, unadjusted Cox-model $P=0.013$, $\mathrm{HR}=3.24$; Cox-model adjusted for risk factors including severe aGvHD $P=0.006, \mathrm{HR}=4.81$ ), which was consistent with the finding for quantitatively modeled 1,25-dihydroxyvitamin-D3 association with the binary outcome TRM reported above. We found the cutoff at $139.5 \mathrm{pM}$ to be the 

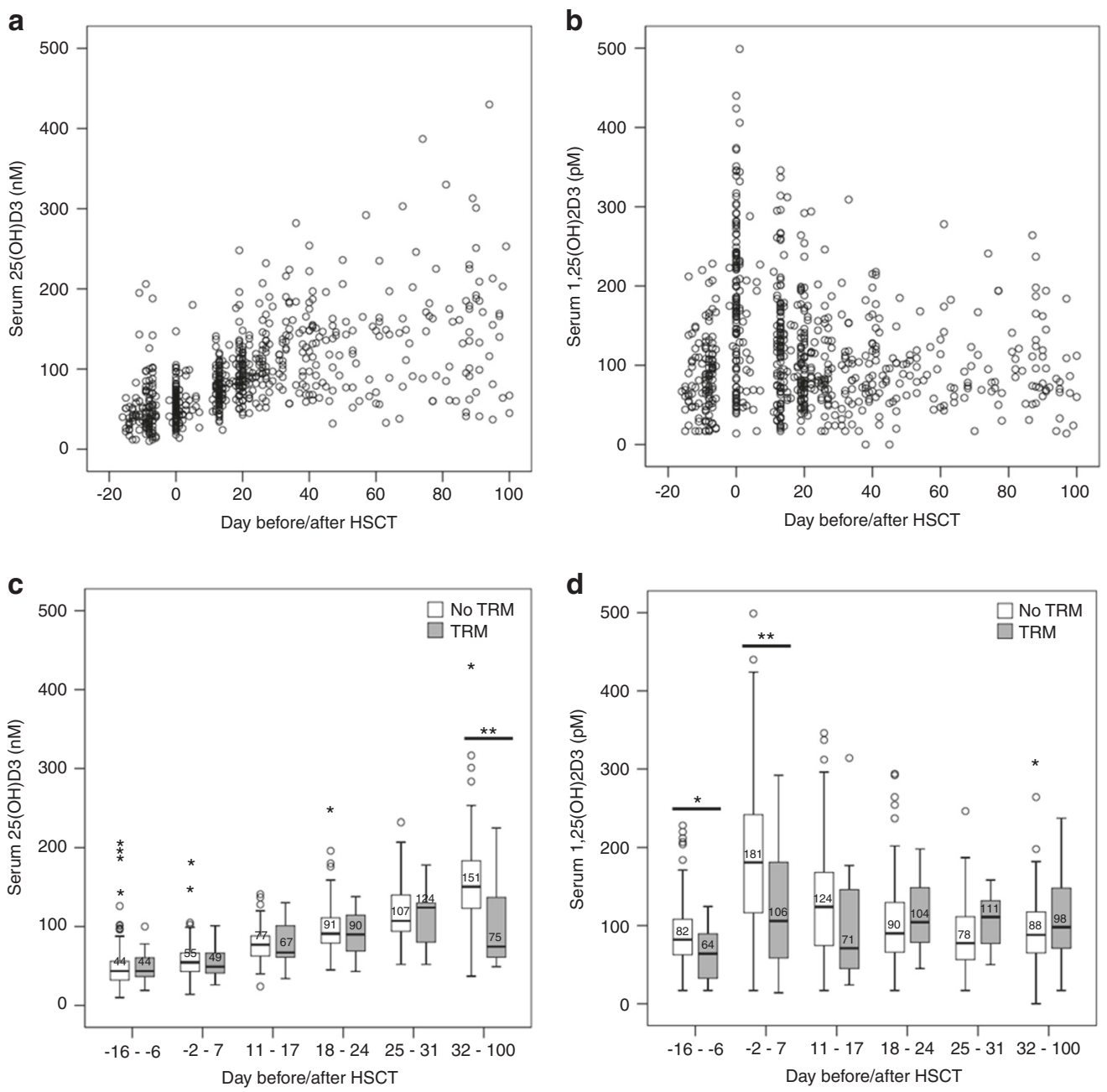

Fig. 1 Time trend of 25-hydroxyvitamin-D3 and 1,25-dihydroxyvitamin-D3 serum levels and association with TRM in the discovery cohort. Shown are a 25-hydroxyvitamin-D3 (25(OH)D3) or b 1,25 -dihydroxyvitamin-D3 $(1,25(\mathrm{OH}) 2 \mathrm{D} 3)$ serum levels in the discovery cohort that were measured repeatedly at hospital admission (baseline, day -16 to -6 ), peritransplant (day -2 to 7 ), during the weekly early follow-up (day 11 to 17,18 to 24,25 to 31 ) and the late follow-up (day 32 to 100 after HSCT) for 143 patients (details see

best to separate those at high risk of TRM from those at low risk yielding an AUC of 0.703 (Fig. 2b). All further analyses were conducted with 1,25-dihydroxyvitamin-D3 levels dichotomized at this optimal cutoff.

\section{Replication cohorts support the predictive value of peritransplant 1,25-dihydroxyvitamin-D3 for 1-year TRM independent of severe aGvHD}

To replicate our finding from the discovery cohort, we collected serum for the relevant time interval, peritransplant, from three independent replication cohorts. Peritransplant 1,25-dihydroxyvitamin-D3 and, for comparison, also peritransplant 25-hydroxyvitamin-D3 were measured yielding an analyzable replication dataset of 365 patients. Our replication

Supplemental Table 1). Also shown is the distribution of $\mathbf{c} 25(\mathrm{OH}) \mathrm{D} 3$ d or $1,25(\mathrm{OH}) 2 \mathrm{D} 3$ levels per time interval separately for patients with or without TRM (23 patients with TRM, 120 patients without). Median serum levels are stated in bold for each boxplot; testing for difference of serum levels between the two groups was performed using Mann-Whitney $\mathrm{U}$ test, $*$ or $* *$ indicates a $P$ value $\leq 0.05$ (nominal significance) or $\leq 0.05 /(6 \times 2)=0.004$ (Bonferroni-corrected significance level), respectively (see Supplemental Table 1 for details).

stage was designed to replicate our initial finding and to generalize to other clinical settings. Of note, the type of vitamin D3 supplementation varied between the three cohorts: same high-dose supplementation as in the discovery cohort (replication cohort I), moderate supplementation (replication cohort II), or no supplementation (replication cohort III). The level of supplementation was reflected in the cohort-specific levels of peritransplant 1,25-dihydroxyvitamin-D3 and 25hydroxyvitamin-D3 (Table 2). When separating the 365 patients in the joint replication data by the optimal cutoff for 1,25-dihydroxyvitamin-D3 at $139.5 \mathrm{pM}$, we found a larger proportion of TRM among patients with low vs. high levels ( $24.2 \%$ vs. $8.9 \%$, Fig. 3a). This was also observed for each of the three replication cohorts separately $(33.3 \%$ vs. $8.2 \%$, $28.0 \%$ vs. $9.4 \%, 19.4 \%$ vs. $10.3 \%$, respectively, Fig. 3 b-d). 
Table 3 Association of late follow-up 25-hydroxyvitaminD3 and peritransplant 1,25dihydroxyvitamin-D3 levels with TRM.

\begin{tabular}{|c|c|c|c|c|c|c|}
\hline \multirow[t]{2}{*}{ Model } & \multicolumn{3}{|c|}{$\begin{array}{l}25(\mathrm{OH}) \mathrm{D} 3 \text { late follow-up (day } 32 \\
\text { to } 100)\end{array}$} & \multicolumn{3}{|c|}{$1,25(\mathrm{OH}) 2 \mathrm{D} 3$ peritransplant (day -2 to 7 ) } \\
\hline & $\begin{array}{l}\text { \#at risk/ } \\
\text { \#TRM }\end{array}$ & $\mathrm{HR}(95 \% \mathrm{CI})$ & $P$ & $\begin{array}{l}\text { \#at risk/ } \\
\text { \#TRM }\end{array}$ & $\mathrm{HR}(95 \% \mathrm{CI})$ & $P$ \\
\hline Unadjusted & $88 / 17$ & & & $143 / 23$ & & \\
\hline Serum level & & $0.98(0.97 ; 0.99)$ & 0.001 & & $0.99(0.99 ; 1.00)$ & 0.001 \\
\hline Adjusted I & $77 / 16$ & & & $128 / 21$ & & \\
\hline Serum level & {$[\mathrm{nM}]$} & $0.98(0.97 ; 0.99)$ & 0.004 & {$[\mathrm{pM}]$} & $0.99(0.98,1.00)$ & 0.002 \\
\hline Age $[y r]$ & & $1.08(1.00 ; 1.16)$ & $\mathbf{0 . 0 3 0}$ & & $1.08(1.02 ; 1.15)$ & 0.013 \\
\hline Male sex & & $0.57(0.19 ; 1.71)$ & 0.314 & & $0.45(0.18 ; 1.13)$ & 0.089 \\
\hline Unrelated donor $^{\mathrm{a}}$ & & $0.61(0.20 ; 1.89)$ & 0.390 & & $1.04(0.39 ; 2.82)$ & 0.935 \\
\hline $\begin{array}{l}\text { Late tumor } \\
\text { stage }^{\mathrm{b}}\end{array}$ & & $1.81(0.66 ; 4.98)$ & 0.250 & & $1.82(0.75 ; 4.41)$ & 0.186 \\
\hline Adjusted II & $77 / 16$ & & & $128 / 21$ & & \\
\hline Serum level & {$[\mathrm{nM}]$} & $0.99(0.98,1.00)$ & 0.069 & {$[\mathrm{pM}]$} & $0.99(0.96 ; 1.00)$ & 0.005 \\
\hline Age $[y r]$ & & $1.05(0.98 ; 1.13)$ & 0.139 & & $1.05(0.99 ; 1.12)$ & 0.087 \\
\hline Sex & & $0.86(0.26 ; 2.81)$ & 0.803 & & $1.40(0.48 ; 4.07)$ & 0.538 \\
\hline Unrelated donor $^{\mathrm{a}}$ & & $0.53(0.16 ; 1.72)$ & 0.287 & & $0.86(0.30 ; 2.45)$ & 0.774 \\
\hline $\begin{array}{l}\text { Late tumor } \\
\text { stage }^{\mathrm{b}}\end{array}$ & & $2.04(0.72 ; 5.84)$ & 0.182 & & $1.72(0.68 ; 4.31)$ & 0.250 \\
\hline Severe $\mathrm{aGvHD}^{\mathrm{c}}$ & & $4.56(1.35 ; 15.39)$ & 0.015 & & $14.81(5.09 ; 43.08)$ & $<0.0005$ \\
\hline Adjusted III & $77 / 16$ & & & $128 / 21$ & & \\
\hline Serum level & {$[\mathrm{nM}]$} & $0.99(0.96,1.00)$ & 0.068 & {$[\mathrm{pM}]$} & $0.99(0.99 ; 1.00)$ & 0.005 \\
\hline Age [yr] & & $1.05(0.98 ; 1.13)$ & 0.144 & & $1.05(0.99 ; 1.12)$ & 0.090 \\
\hline Sex & & $0.86(0.26 ; 2.82)$ & 0.808 & & $1.37(0.46 ; 4.12)$ & 0.576 \\
\hline Unrelated donor $^{\mathrm{a}}$ & & $0.52(0.16 ; 1.72)$ & 0.286 & & $0.85(0.29 ; 2.44)$ & 0.756 \\
\hline $\begin{array}{l}\text { Late tumor } \\
\text { stage }^{\mathrm{b}}\end{array}$ & & $2.03(0.70 ; 5.88)$ & 0.194 & & $1.73(0.69 ; 4.34)$ & 0.247 \\
\hline Severe $\mathrm{aGvHD}^{\mathrm{c}}$ & & $4.56(1.35 ; 15.44)$ & 0.015 & & $14.81(5.08 ; 43.13)$ & $<0.0005$ \\
\hline $\begin{array}{l}25(\mathrm{OH}) \mathrm{D} 3 \mathrm{~d}- \\
2-7^{\mathrm{d}}\end{array}$ & {$[\mathrm{nM}]$} & $1.00(0.97 ; 1.03)$ & 0.929 & {$[\mathrm{pM}]$} & $1.00(0.98 ; 1.02)$ & 0.871 \\
\hline
\end{tabular}

Shown are results from Cox proportional hazards models for the association of late follow-up 25hydroxyvitamin-D3 $(25(\mathrm{OH}) \mathrm{D} 3$, day 32 to 100$)$ or peritransplant 1,25-dihydroxyvitamin-D3 $(1,25(\mathrm{OH}) 2 \mathrm{D} 3$, day -2 to 7 ) with TRM without and with adjustment for risk factors and sensitivity analyses. $P$ values $\leq 0.05$ are marked in bold.

TRM treatment-related mortality, 25( OH)D3 25-hydroxyvitamin-D3, 1,25( OH)2D3 1,25-dihydroxyvitamin$\mathrm{D} 3, H R$ hazard ratio, $a G v H D$ acute Graft-versus-Host disease.

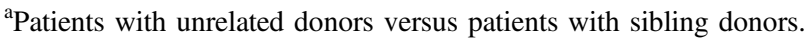

${ }^{\mathrm{b}}$ Classification according to EBMT risk score [50] late stage versus early/intermediate stage.

${ }^{c}$ Any occurrence of aGvHD 3-4 [14] within 1 year after HSCT versus no occurrence of aGvHD 3-4.

${ }^{\mathrm{d}}$ Peritransplant (day -2 to 7 ) 25-hydroxyvitamin-D3.
We also found clearly separated Kaplan-Meier survival curves in each of the replication cohorts and overall.

When applying Cox proportional hazards models to the joint replication data (Table 4), we found statistically significant association for low 1,25-dihydroxyvitamin-D3 with increased one-year TRM that was very robust upon different approaches for adjustment (without any covariates, adjusting for risk factors excluding severe aGvHD or for risk factors including severe aGvHD: $P<0.0005$, HR $=3.51 ; P<0.0005, \mathrm{HR}=3.30 ; P=0.001, \mathrm{HR}=3.31$, respectively). Of note, adjusting for the Karnofsky performance score (KPS) at time of transplantation did not change the statistically significant association between 1,25-dihydroxyvitamin-D3 and one-year TRM (results not shown).

To address the question whether absolute levels of peritransplant 1,25-dihydroxyvitamin-D3 are responsible for the outcome or whether peritransplant 1,25-dihydroxyvitamin-D3 levels are a surrogate marker for another biological process, we normalized peritransplant 1,25-dihydroxyvitamin-D3 


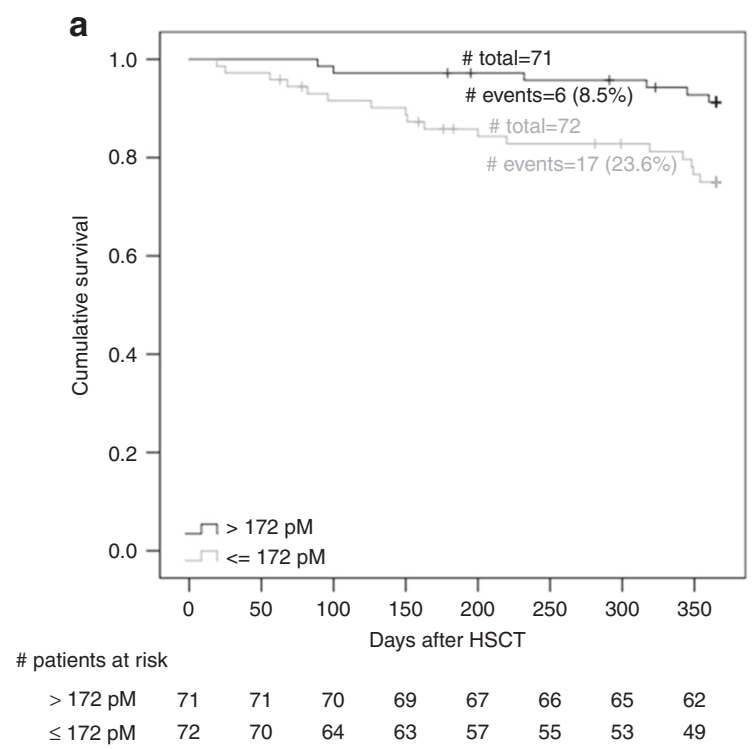

Fig. 2 Treatment-related survival and receiver-operatingcharacteristics curve comparing patients with high versus low peritransplant 1,25-dihydroxyvitamin-D3 serum levels in the discovery cohort. a Shown is the Kaplan-Meier curve comparing patients above versus below median peritransplant 1,25-dihydroxyvitaminD3 serum levels (day -2 to 7 , median $=172 \mathrm{pM}$ ). b Also shown is the

levels to peritransplant 25-hydroxyvitamin-D3 levels. The discrimination between patients with and without TRM disappeared in the replication datasets I-III (Supplemental Fig. 2). This indicates that the absolute levels of 1,25dihydroxyvitmain-D3 are indeed crucial. However, in the discovery cohort the discrimination between patients with and without TRM was still possible after normalization. Based on these data it is not completely clear whether the absolute levels alone are responsible for the outcome.

\section{Subgroup analysis for patients with severe aGvHD and those without severe aGvHD}

We followed the finding that low 1,25-dihydroxyvitamin-D3 predicted TRM independent of severe aGvHD by an analysis separated by aGvHD status. We found shorter median timeto-death and higher Cox-model-derived HR estimates for patients with low vs. high 1,25-dihydroxyvitamin-D3 levels in all four groups (Table S2): (1) in patients without severe aGvHD in the discovery (163 days vs. 353 days comparing patients $\leq 139.5 \mathrm{pM}$ vs. patients $>139.5 \mathrm{pM}$; $\mathrm{HR}=7.83, P=$ $0.010)$, (2) in patients without severe aGvHD in the joint replication data (122 days vs. 144 days; $H R=5.28, P=$ $0.001)$, (3) in patients with severe aGvHD in the discovery (150 days vs. 232 days; $\mathrm{HR}=5.43, P=0.006$ ), and (4) in patients with severe aGvHD in the joint replication data (113 days vs. 176 days; $\mathrm{HR}=2.06, P=0.135$ ). Given the consistent directionality in the difference in median time-todeath and in HR estimates across these four groups, the lack

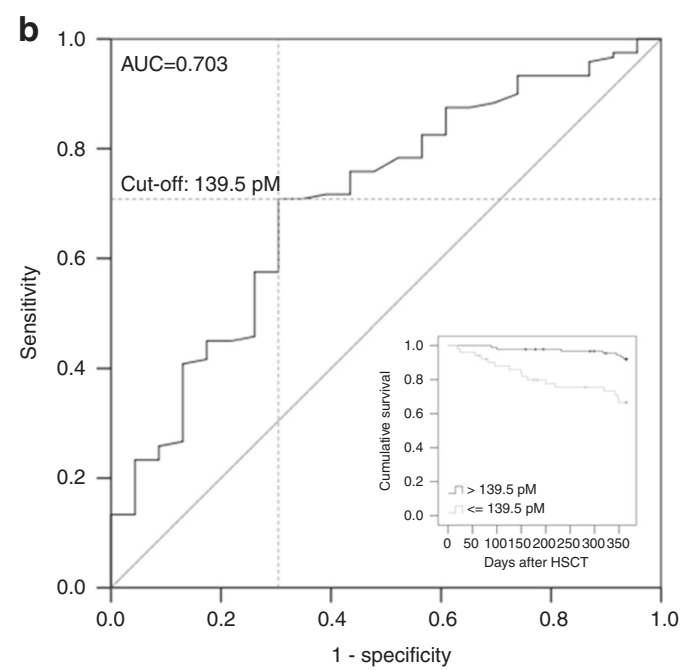

Receiver-Operating-Characteristics (ROC) curve for the ability of peritransplant 1,25-dihydroxyvitamin-D3 serum levels to predict TRM. The best cutoff calculated by Youden-Index [15] was derived as $139.5 \mathrm{pM}$. Embedded in $\mathbf{b}$ is the Kaplan-Meier curve using this best cutoff rather than the median in the discovery cohort.

of statistical significance in some of the groups may be due to the low number of patients per group and thus limited power to detect effects group-specifically. The consistent pattern across the four groups can be visualized in Kaplan-Meiercurves (Fig. 4). This supports the notion that the higher mortality for patients with low vs. high 1,25-dihydroxyvitamin-D3 levels is apparent in patients with severe aGvHD as well as those without, which is in line with the previous results that the effect was independent from severe aGvHD as shown in the models adjusting for severe aGvHD.

\section{Discussion}

Our data of altogether 508 patients undergoing HSCT highlighted higher 1,25-dihydroxyvitamin-D3 levels at the time of HSCT to be a strong predictor for one-year TRM independent of severe aGvHD. This predictor was independent of baseline characteristics known to affect TRM and independent of 25hydroxyvitamin-D3 levels. We identified the optimal threshold of $139.5 \mathrm{pM} 1,25$-dihydroxyvitamin-D3 to detect patients at high risk for TRM and replicated our finding in independent replication data consisting of 365 patients from three different clinical settings.

To our knowledge, our present study is the first study on 1,25-dihydroxyvitamin-D3 in the context of allogeneic HSCT and with 508 patients the largest study on vitamin D metabolites in the context of allogeneic HSCT. Up to now, all published studies on vitamin D included less patients [17, 18]. 
Fig. 3 Treatment-related survival in the replication cohort comparing patients with peritransplant 1,25 dihydroxyvitamin-D3 serum levels above and below the cutoff 139.5 pM. Shown are Kaplan-Meier curves comparing patients with peritransplant 1,25-dihydroxyvitaminD3 serum levels (day -2 to 7 ) above versus below the cutoff $139.5 \mathrm{pM}$ in a the joint replication cohorts, $\mathbf{b}$ replication cohort I, c replication cohort II, and $\mathbf{d}$ replication cohort III. a
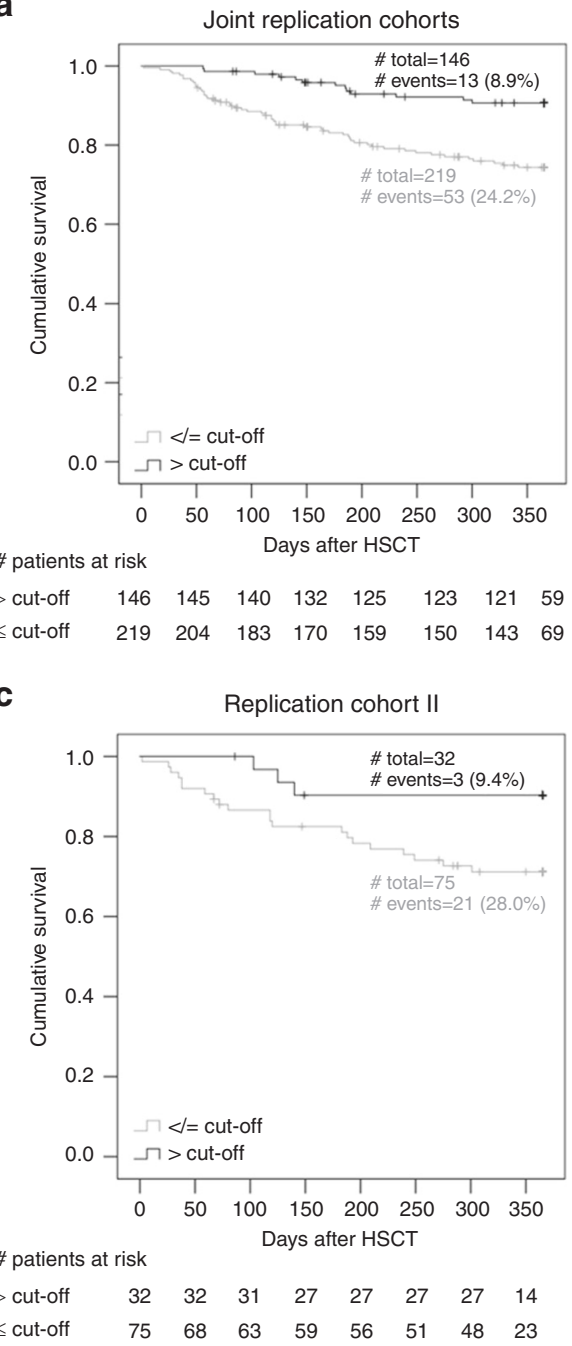

b

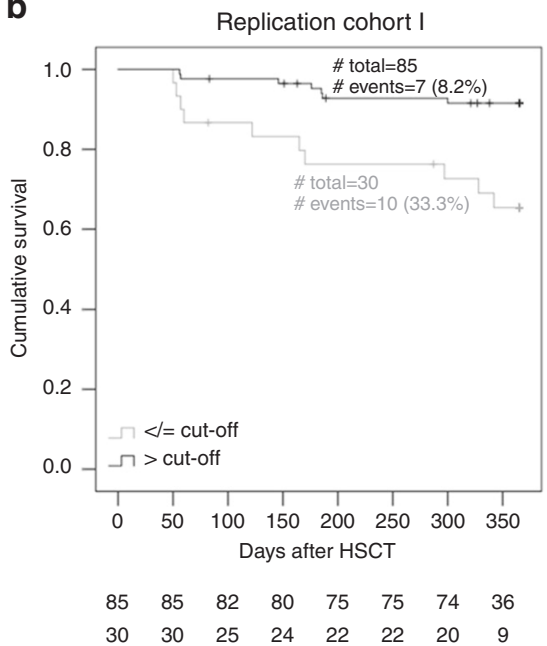

d
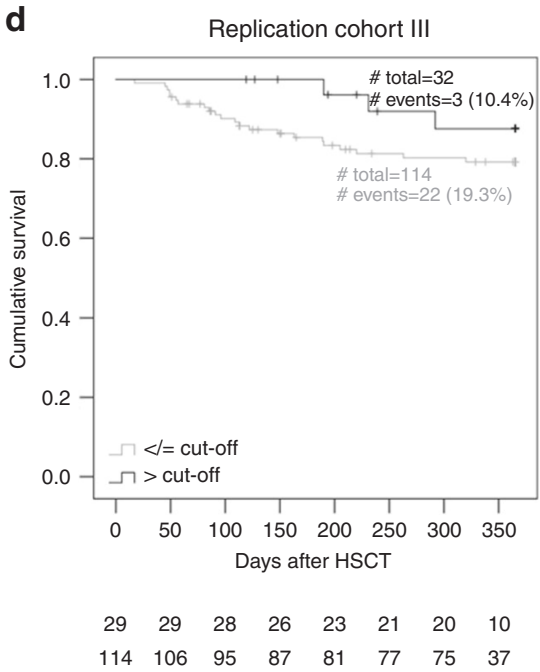

Existing studies on vitamin D in the context of allogeneic HSCT are dealing with the role of 25-hydroxyvitamin-D3, the precursor of 1,25-dihydroxyvitamin-D3. A number of reports has described insufficiency for 25-hydroxyvitaminD3 in patients undergoing allogeneic $\operatorname{HSCT}[2,5,6,19]$. As a consequence, we and others used different approaches to increase vitamin D levels in patients undergoing HSCT [7, 12, 20-22]. At present, the role of 25-hydroxyvitaminD3 for survival after HSCT has been examined in eight studies [3-5, 7, 18, 23-25]. In four studies early low 25hydroxyvitamin-D3 levels were associated with increased overall mortality [4, 5, 18, 25]. In contrast, no significant impact of early 25-hydroxyvitamin-D3 serum levels on overall survival was described in four studies [3, 7, 23, 24]. In line, also in our study low peritransplant 25hydroxyvitamin-D3 levels were no risk factor for mortality. However, the primary endpoint of our analysis was TRM, not overall mortality. Conflicting data have also been published looking at 25-hydroxyvitamin-D3 and association with aGvHD [5, 23, 26] and cGvHD [4, 5, 7, 26-28]. When we tested for an association of severe aGvHD or cGvHD with 1,25(OH)2D3 levels, respectively, no significant association was detected.

We found that the association of low late follow-up 25hydroxyvitamin-D3 levels with TRM vanished upon accounting for severe aGvHD in the Cox-model. Since severe aGvHD is a major risk factor for TRM [29], one might speculate, that the decreased 25-hydroxyvitamin-D3 levels we observed in the late follow-up of patients with TRM were - at least in part_-due to severe aGvHD, which is characterized by gastrointestinal tract involvement and often includes diarrhea [29]. Indeed, also Wallace et al. found the association of 25-hydroxyvitamin-D3 deficiency 100 days post-HSCT with reduced mortality in pediatric patients to be a consequence of aGvHD rather than vitamin $\mathrm{D}$ deficiency per se [5].

In contrast to 25-hydroxyvitamin-D3, the association of peritransplant 1,25-dihydroxyvitamin-D3 levels with TRM both in the discovery and in the replication data was also robust upon accounting for factors known to be 
Table 4 Association of peritransplant 1,25 dihydroxyvitamin-D3 levels dichotomized at $139.5 \mathrm{pM}$ with TRM in discovery cohort and in joint replication cohorts.

\begin{tabular}{|c|c|c|c|c|c|c|}
\hline & \multicolumn{3}{|c|}{$\begin{array}{l}\text { Peritransplant } 1,25(\mathrm{OH}) 2 \mathrm{D} 3 \\
\text { discovery data }\end{array}$} & \multicolumn{3}{|c|}{$\begin{array}{l}\text { Peritransplant } 1,25(\mathrm{OH}) 2 \mathrm{D} 3 \text { joint } \\
\text { replication data }\end{array}$} \\
\hline & $\begin{array}{l}\text { \#at risk/ } \\
\text { \#TRM }\end{array}$ & HR $(95 \% \mathrm{CI})$ & $P$ & $\begin{array}{l}\text { \#at risk/ } \\
\text { \#TRM }\end{array}$ & HR $(95 \% \mathrm{CI})$ & $P$ \\
\hline Unadjusted & $143 / 23$ & & & $365 / 66$ & & \\
\hline $\begin{array}{l}\text { Serum level } \\
\leq 139.5 \mathrm{pM}^{\mathrm{a}}\end{array}$ & & $5.16(2.12 ; 12.57)$ & $<0.0005$ & & $3.51(1.79 ; 6.88)$ & $<0.0005$ \\
\hline Adjusted I & $128 / 21$ & & & $364 / 66$ & & \\
\hline $\begin{array}{l}\text { Serum level } \\
\leq 139.5 \mathrm{pM}^{\mathrm{a}}\end{array}$ & & $6.10(2.24 ; 16.63)$ & $<0.0005$ & & $3.30(1.70 ; 6.44)$ & $<0.0005$ \\
\hline Age $[y r]$ & & $1.08(1.01 ; 1.15)$ & 0.018 & & $1.05(1.02 ; 1.07)$ & 0.001 \\
\hline Male sex & & $0.45(0.19 ; 1.10)$ & 0.081 & & $0.92(0.55 ; 1.54)$ & 0.749 \\
\hline Unrelated donor ${ }^{\mathrm{b}}$ & & $0.99(0.39 ; 2.54)$ & 0.986 & & $2.77(1.25 ; 6.13)$ & 0.012 \\
\hline Late tumor stage $\mathrm{c}^{\mathrm{c}}$ & & $1.81(0.073 ; 4.46)$ & 0.197 & & $1.03(0.61 ; 1.72)$ & 0.919 \\
\hline Adjusted II & $128 / 21$ & & & $361 / 63$ & & \\
\hline $\begin{array}{l}\text { Serum level } \\
\leq 139.5 \mathrm{pM}^{\mathrm{a}}\end{array}$ & & $6.00(2.16 ; 16.63)$ & 0.001 & & $3.31(1.68 ; 6.53)$ & 0.001 \\
\hline Age $[\mathrm{yr}]$ & & $1.05(0.99 ; 1.12)$ & 0.134 & & $1.04(1.01 ; 1.07)$ & 0.006 \\
\hline Male sex & & $1.21(0.44 ; 3.33)$ & 0.712 & & $0.95(0.56 ; 1.61)$ & 0.848 \\
\hline Unrelated donor $^{\mathrm{b}}$ & & $0.82(0.31 ; 2.21)$ & 0.700 & & $2.49(1.11 ; 5.56)$ & 0.026 \\
\hline Late tumor stage $\mathrm{c}^{\mathrm{c}}$ & & $1.63(0.63 ; 4.26)$ & 0.317 & & $0.99(0.58 ; 1.69)$ & 0.960 \\
\hline Severe $a G v H D^{d}$ & & $16.18(5.56 ; 47.07)$ & $<0.0005$ & & $4.96(2.91 ; 8.47)$ & $<0.0005$ \\
\hline
\end{tabular}

Shown are results from Cox proportional hazards models based on the 143 patients (23 TRM) of the discovery cohort and 365 patients (66 TRM) combining the three replication cohorts. Models for the joint replication cohorts are stratified by cohort. $P$ values $\leq 0.05$ are marked in bold.

$T R M$ treatment-related mortality, 1,25(OH)2D3 1,25-dihydroxyvitamin-D3, $H R$ hazard ratio, $a G v H D$ acute Graft-versus-Host disease.

${ }^{\mathrm{a}} 1,25(\mathrm{OH}) 2 \mathrm{D} 3$ level d-2-7 $\leq />$ cutoff $139.5 \mathrm{pM}$.

${ }^{\mathrm{b}}$ Patients with unrelated donors versus patients with sibling donors.

${ }^{c}$ Classification according to EBMT risk score [50] late stage versus early/intermediate stage.

${ }^{\mathrm{d}}$ Any occurrence of aGvHD 3-4 [14] within 1 year after HSCT versus no occurrence of aGvHD 3-4. critical for TRM, including severe aGvHD. No study up to now has addressed the role of 1,25-dihydroxyvitaminD3 in HSCT. In renal transplantation (Tx) low 1,25dihydroxyvitamin-D3 levels have been reported to be associated with increased mortality [30]. Others observed low 1,25-dihydroxyvitamin-D3 levels to be indicative for graft rejection and/or infections after renal Tx [31, 32]. However, since 1,25-dihydroxyvitamin-D3 is produced in the kidney, low levels of 1,25-dihydroxyvitamin-D3 during renal $\mathrm{Tx}$ might be indicative for reduced renal function [30]. Low postoperative (until d21 after Tx) 1,25-dihydroxyvitamin-D3 concentrations were also shown to be independent risk factors for 1-year mortality following cardiac Tx [33].

Whether these observations implicate a causal relationship between low 1,25-dihydroxyvitamin-D3 and adverse Tx outcome or whether the high 1,25-dihydroxyvitamin-D3 is indicative for a better general constitution of a patient remains unclear. There is some evidence of a causal relationship: the administration of 1,25-dihydroxyvitamin-D3 in rat liver Tx models reduced mortality and graft rejection [34, 35]. Similarly, Pakkala et al. observed an analog of 1,25-dihydroxyvitamin-D3 to prevent aGvHD in a rat model for HSCT [10]. Further evidence for a causal link is provided by the fact that vitamin $\mathrm{D}$ receptor (VDR) gene polymorphisms are associated with development of aGvHD in humans [11]. In line, a recent study reported a decreased incidence of $\mathrm{cGvHD}$ upon vitamin D supplementation of patients with a certain VDR genotype [12]. Interestingly, VDR gene polymorphisms have also been characterized as risk factors for graft rejection after liver Tx [36]. Zhang et al. showed that the beneficial effect of 1,25-dihydroxyvitamin-D3 in rat liver Tx involves the reduction of proinflammatory pathways [34] pointing to an active immunomodulatory role of 1,25-dihydroxyvitaminD3 in improving the outcome. Consistently, administration of 1,25-dihydroxyvitamin-D3 or an analogon to patients receiving renal $\mathrm{Tx}$ was found to reduce the risk of adverse events [31, 37]. 

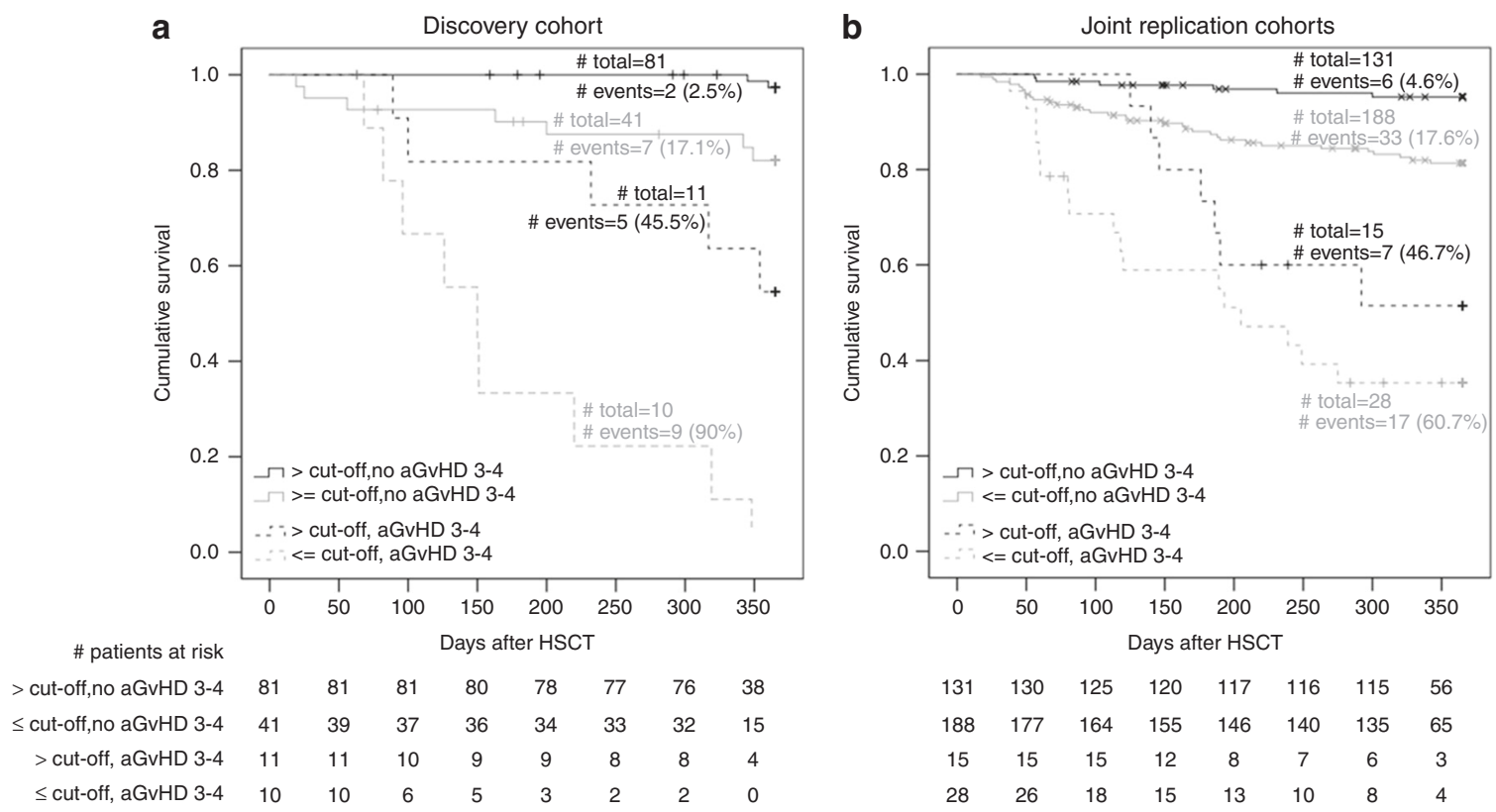

Fig. 4 Treatment-related survival separated by severe aGvHD status in discovery cohort and joint replication cohorts comparing patients with peritransplant 1,25-dihydroxyvitamin-D3 serum levels above and below the cutoff 139.5 pM. Shown are Kaplan-Meier curves comparing patients with peritransplant 1,25-dihydroxyvitamin-D3 serum

A major question arising from our study is, why patients with low peritransplant 1,25-dihydroxyvitaminD3 levels are at 3.3-fold risk for TRM within 1 year compared to patients with high levels in our data. One possibility might be that a high 1,25-dihydroxyvitamin-D3 level represents a marker for a patient's better overall condition. On the other hand, high 1,25-dihydroxyvitaminD3 levels might actively mediate a beneficial functional effect. We tried to address this question by normalizing the peritransplant 1,25-dihydroxyvitamin-D3 levels to peritransplant 25-hydroxyvitamin-D3 levels but did not receive a clear result. In this context it needs to be emphasized that the differences in 1,25-dihydroxyvitaminD3 levels observed in our study are not a result of impaired renal function in some patients since renal function of our patients was tightly controlled. Furthermore, our finding was robust upon adjusting for baseline factors displaying the overall condition of patients like age, conditioning or tumor stage prior to HSCT. Importantly, 1,25-dihydroxyvitamin-D3 is not limited to renal production: also immune cells, especially myeloid cells are known to produce the active vitamin $\mathrm{D}$ metabolite and thereby contribute to local immune regulation $[9,38]$. The early peak in 1,25-dihydroxyvitamin-D3 levels could-at least in part - be due to increased macrophage activity and could be indicative for patients harboring macrophage populations with primarily immune regulatory capacities. Another possibility could be that high circulating concentrations of levels (day -2 to 7 ) above versus below the cutoff $139.5 \mathrm{pM}$ separately for the group of patients without severe aGvHD (aGvHD 3-4) and the group of patients with severe aGvHD $\mathbf{a}$ in the discovery cohort and $\mathbf{b}$ in the joint replication cohorts.

1,25-dihydroxyvitamin-D3 at the time of HSCT directly modulate one or several critical factors known to be crucial for HSCT outcome: 1,25-dihydroxyvitamin-D3 has been demonstrated to drive differentiation of monocytes during hematopoiesis [39]. Interestingly, higher levels of monocytes following HSCT have been correlated with better overall survival [40-42]. In light of these findings one could speculate that the availability of 1,25-dihydroxyvitamin-D3 at the time of HSCT improves the development of monocytes from the graft, which is beneficial for patient survival. Furthermore, also remaining immune cells in the recipient might be affected by high 1,25dihydroxyvitamin-D3 levels around HSCT since 1,25dihydroxyvitamin-D3 has been shown e.g., to tolerize dendritic cells and to induce regulatory $\mathrm{T}$ cells [9, 43-45] leading to a more immunosuppressive environment in the patient. A critical risk factor for TRM is severe aGvHD, which predominantly affects the gut. Although aGvHD typically develops during the follow-up, early events around the time of HSCT, as conditioning-induced damage of the intestinal barrier or microbial changes due to conditioning or use of prophylactic antibiotics, are known to be critical for the development of GvHD [46, 47]. A role of 1,25-dihydroxyvitamin-D3 for gut homeostasis is supported by murine models, showing that VDR -/- mice exhibit significant shifts in the microbiota relative to control mice [48] and VDR signaling preserves the intestinal epithelial barrier integrity [49]. Therefore, high 
1,25-dihydroxyvitamin-D3 levels around HSCT may strengthen the intestinal epithelial barrier function in HSCT patients and exert immunoregulatory effects $[44,45]$ thereby possibly ameliorating gut GvHD. In case of a direct effect of high 1,25-dihydroxyvitamin-D3 levels at the time of HSCT, pretransplant supplementation of HSCT patients with vitamin D metabolites would be highly recommended as supportive therapy.

A limitation of the current study is that retrospective studies are unable to correct for changes in practice at each facility over time. Each cohort was transplanted at different times and under different protocols. Furthermore, historical controls are used and there are limitations to using such controls for studies. However, a clear strength of our data are our independent replication stage that replicates the initial finding and generalizes the effect to other clinical settings including other modes of vitamin D supplementation or other clinical approaches towards concomitant therapy. This overcomes the potentially perceived limitation of the discovery cohort, that the high-dose vitamin D3 supplementation administered to the discovery cohort patients is not standard care of HSCT patients. While each of the replication cohorts is not large and thus we refrained from statistical testing by replication cohort separately, the joint replication data with 365 HSCT patients are substantial and results are stable between discovery and replication as well as across different analyses approaches and models with different baseline risk factor control. Therefore, our data suggests 1,25-dihydroxyvitamin-D3 at the time of HSCT as a predictive factor for TRM.

In summary, our data highlight the apparently underestimated role of 1,25-dihydroxyvitamin-D3 and its value to predict outcome of allogeneic HSCT. Whether supplementation with 1,25-dihydroxyvitamin-D3 or 1,25-dihydroxyvitamin-D3 analogs could improve patient survival needs to be addressed in future prospective studies.

Funding This study was funded by research grants from the Wilhelm-Sander Stiftung, Munich, Projektnummer 2017.020.1 and the Deutsche Forschungsgemeinschaft (DFG, German Research Foundation) Projektnummern HO1142/2-2, KR1418/10-2 and Projektnummer 324392634-TRR 221 project B12 (HB, KP, and MK). Open access funding provided by Projekt DEAL.

Author contributions KP collected data, performed analyses, and wrote the manuscript. PJS was involved in data collection and manuscript preparation. FA, MG, TR, and CM collected data. KR, KS, $\mathrm{DaWe}$, and DaWo were involved in data collection and discussed the data. HB, NK, WH, and EH discussed the data. KISt performed analyses and discussed the data. IMH and MK designed the approach, supervised the analysis, and wrote the manuscript.

\section{Compliance with ethical standards}

Conflict of interest The authors declare that they have no conflict of interest.
Publisher's note Springer Nature remains neutral with regard to jurisdictional claims in published maps and institutional affiliations.

Open Access This article is licensed under a Creative Commons Attribution 4.0 International License, which permits use, sharing, adaptation, distribution and reproduction in any medium or format, as long as you give appropriate credit to the original author(s) and the source, provide a link to the Creative Commons license, and indicate if changes were made. The images or other third party material in this article are included in the article's Creative Commons license, unless indicated otherwise in a credit line to the material. If material is not included in the article's Creative Commons license and your intended use is not permitted by statutory regulation or exceeds the permitted use, you will need to obtain permission directly from the copyright holder. To view a copy of this license, visit http://creativecommons. org/licenses/by/4.0/.

\section{References}

1. Gooley TA, Chien JW, Pergam SA, Hingorani S, Sorror ML, Boeckh M, et al. Reduced mortality after allogeneic hematopoieticcell transplantation. N Engl J Med. 2010;363:2091-101. https://doi. org/10.1056/NEJMoa1004383.

2. Joseph RW, Alousi A, Konda B, Komanduri K, Neumann J, Trevino C, et al. High incidence of vitamin D deficiency in patients undergoing allogeneic stem cell transplantation. Am J Hematol. 2011;86:954-6. https://doi.org/10.1002/ajh.22143.

3. Bahr L, von, Blennow O, Alm J, Bjorklund A, Malmberg K-J, Mougiakakos D, et al. Increased incidence of chronic GvHD and CMV disease in patients with vitamin D deficiency before allogeneic stem cell transplantation. Bone Marrow Transpl. 2015;50:1217-23. https://doi.org/10.1038/bmt.2015.123.

4. Hansson MEA, Norlin A-C, Omazic B, Wikstrom A-C, Bergman $\mathrm{P}$, Winiarski J, et al. Vitamin d levels affect outcome in pediatric hematopoietic stem cell transplantation. Biol Blood Marrow Transpl. 2014;20:1537-43. https://doi.org/10.1016/j.bbmt.2014. 05.030 .

5. Wallace G, Jodele S, Howell J, Myers KC, Teusink A, Zhao X, et al. Vitamin D deficiency and survival in children after hematopoietic stem cell transplant. Biol Blood Marrow Transpl. 2015;21:1627-31. https://doi.org/10.1016/j.bbmt.2015.06.009.

6. Joseph R, Jabbar S, Reddy M, Houghton DE, Yun T, Tan X, et al. Association of pre-allogeneic hematopoietic stem cell transplant 25-hydroxy-vitamin D level and development of acute skin graftversus-host-disease: a retrospective analysis of 154 patients. JCO. 2017;35:e18539. https://doi.org/10.1200/JCO.2017.35.15_suppl. e18539.

7. Caballero-Velazquez T, Montero I, Sanchez-Guijo F, Parody R, Saldana R, Valcarcel D, et al. Immunomodulatory effect of vitamin $\mathrm{D}$ after allogeneic stem cell transplantation: results of a prospective multicenter clinical trial. Clin Cancer Res. 2016;22:5673-81. https://doi.org/10.1158/1078-0432.CCR-16-0238.

8. Prietl B, Treiber G, Pieber TR, Amrein K. Vitamin D and immune function. Nutrients. 2013;5:2502-21. https://doi.org/ 10.3390/nu5072502.

9. Fritsche J, Mondal K, Ehrnsperger A, Andreesen R, Kreutz M. Regulation of 25-hydroxyvitamin D3-1 alpha-hydroxylase and production of 1 alpha,25-dihydroxyvitamin D3 by human dendritic cells. Blood. 2003;102:3314-6. https://doi.org/10.1182/ blood-2002-11-3521.

10. Pakkala I, Taskinen E, Pakkala S, Raisanen-Sokolowski A. MC1288, a vitamin D analog, prevents acute graft-versus-host disease in rat bone marrow transplantation. Bone Marrow Transpl. 2001;27:863-7. https://doi.org/10.1038/sj.bmt.1702873. 
11. Middleton PG, Cullup H, Dickinson AM, Norden J, Jackson GH, Taylor PRA, et al. Vitamin D receptor gene polymorphism associates with graft-versus-host disease and survival in HLAmatched sibling allogeneic bone marrow transplantation. Bone Marrow Transpl. 2002;30:223-8. https://doi.org/10.1038/sj.bmt. 1703629.

12. Carrillo-Cruz E, Garcia-Lozano JR, Marquez-Malaver FJ, Sanchez-Guijo FM, Montero Cuadrado I, Ferra I, et al. Vitamin D modifies the incidence of graft-versus-host disease after allogeneic stem cell transplantation depending on the vitamin D receptor (VDR) polymorphisms. Clin Cancer Res. 2019;25:4616-23. https://doi.org/10.1158/1078-0432.CCR-18-3875.

13. Liebisch G, Matysik S. Accurate and reliable quantification of 25hydroxy-vitamin $\mathrm{D}$ species by liquid chromatography high-resolution tandem mass spectrometry. J Lipid Res. 2015;56:1234-9. https://doi. org/10.1194/jlr.D058511.

14. Marks R, Potthoff K, Hahn J, Ihorst G, Bertz H, Spyridonidis A, et al. Reduced-toxicity conditioning with fludarabine, BCNU, and melphalan in allogeneic hematopoietic cell transplantation: particular activity against advanced hematologic malignancies. Blood. 2008;112:415-25. https://doi.org/10.1182/blood-2007-08-104745.

15. YOUDEN WJ. Index for rating diagnostic tests. Cancer. 1950;3: 32-5.

16. Rice K, Higgins JPT, Lumley T. A re-evaluation of fixed effect(s) meta-analysis. J R Stat Soc A. 2017;181:205-27. https://doi.org/ 10.1111/rssa. 12275

17. Ros-Soto J, Anthias C, Madrigal A, Snowden JA. Vitamin D: is it important in haematopoietic stem cell transplantation? A review. Bone Marrow Transpl. 2018. https://doi.org/10.1038/s41409-0180377-0.

18. Radujkovic A, Kordelas L, Krzykalla J, Beelen DW, Benner A, Lehners N, et al. Pretransplant vitamin D deficiency is associated with higher relapse rates in patients allografted for myeloid malignancies. J Clin Oncol. 2017;35:3143-52. https://doi.org/10. 1200/JCO.2017.73.0085.

19. Kreutz M, Eissner G, Hahn J, Andreesen R, Drobnik W, Holler E. Variations in 1 alpha,25-dihydroxyvitamin D3 and 25hydroxyvitamin D3 serum levels during allogeneic bone marrow transplantation. Bone Marrow Transpl. 2004;33:871-3. https:// doi.org/10.1038/sj.bmt.1704448.

20. Kreutz M, Karrer S, Hoffmann P, Gottfried E, Szeimies RM, Hahn $\mathrm{J}$, et al. Whole-body UVB irradiation during allogeneic hematopoietic cell transplantation is safe and decreases acute graft-versus-host disease. J Invest Dermatol. 2012;132:179-87. https://doi.org/10.1038/jid.2011.255.

21. Wallace G, Jodele S, Myers KC, Dandoy CE, El-Bietar J, Nelson A, et al. Single ultra-high-dose cholecalciferol to prevent vitamin D deficiency in pediatric hematopoietic stem cell transplantation. Biol Blood Marrow Transpl. 2018;24:1856-60. https://doi.org/10. 1016/j.bbmt.2018.05.019.

22. Wallace G, Jodele S, Myers KC, Dandoy CE, El-Bietar J, Nelson A, et al. Vitamin D deficiency in pediatric hematopoietic stem cell transplantation patients despite both standard and aggressive supplementation. Biol Blood Marrow Transpl. 2016;22:1271-4. https://doi.org/10.1016/j.bbmt.2016.03.026.

23. Glotzbecker B, Ho VT, Aldridge J, Kim HT, Horowitz G, Ritz J, et al. Low levels of 25-hydroxyvitamin D before allogeneic hematopoietic SCT correlate with the development of chronic GVHD. Bone Marrow Transpl. 2013;48:593-7. https://doi.org/10. 1038/bmt.2012.177.

24. Campos DJ, Kujew Biagini GL, Moreira Funke VA, Sales Bonfim CM, Boguszewski CL, Cochenski Borba VZ. Vitamin D deficiency in children and adolescents submitted to hematopoietic stem cell transplantation. Rev Bras Hematol Hemoter. 2014;36:126-31. https://doi.org/10.5581/1516-8484.20140029.
25. Beebe K, Magee K, McNulty A, Stahlecker J, Salzberg D, Miller $\mathrm{H}$ et al. Vitamin D deficiency and outcomes in pediatric hematopoietic stem cell transplantation. Pediatr Blood Cancer. 2018. https://doi.org/10.1002/pbc.26817.

26. Chiengthong K, Cheungpasitporn W, Thongprayoon C, Lertjitbanjong P, Cato LD, Bathini T et al. Vitamin D deficiency is not associated with graft versus host disease after hematopoietic stem cell transplantation: a meta-analysis. J Evid Based Med. 2020. https://doi.org/10.1111/jebm.12383.

27. Silva F, Pérez-Simón JA, Caballero-Velazquez T, Sánchez-Guijo FM, Villanueva-Gomez F, Vazquez L, et al. Effect of vitamin D treatment in chronic GVHD. Bone Marrow Transpl. 2011;46: 1395-7. https://doi.org/10.1038/bmt.2010.317.

28. Katić M, Pirsl F, Steinberg SM, Dobbin M, Curtis LM, Pulanić D, et al. Vitamin D levels and their associations with survival and major disease outcomes in a large cohort of patients with chronic graft-vs-host disease. Croat Med J. 2016;57:276-86. https://doi. org/10.3325/cmj.2016.57.276.

29. Ferrara JL, Levine JE, Reddy P, Holler E. Graft-versus-host disease. Lancet. 2009;373:1550-61. https://doi.org/10.1016/S01406736(09)60237-3.

30. Keyzer CA, Riphagen IJ, Joosten MM, Navis G, Muller Kobold $\mathrm{AC}$, Kema IP, et al. Associations of $25(\mathrm{OH})$ and $1,25(\mathrm{OH}) 2$ vitamin $\mathrm{D}$ with long-term outcomes in stable renal transplant recipients. J Clin Endocrinol Metab. 2015;100:81-9. https://doi. org/10.1210/jc.2014-3012.

31. Moscarelli L, Antognoli G, Buti E, Dervishi E, Fani F, Caroti L, et al. 1,25 Dihydroxyvitamin D circulating levels, calcitriol administration, and incidence of acute rejection, CMV infection, and polyoma virus infection in renal transplant recipients. Clin Transpl. 2016;30:1347-59. https://doi.org/10.1111/ctr.12829.

32. Falkiewicz K, Boratynska M, Speichert-Bidzinska B, Magott-Procelewska M, Biecek P, Patrzalek D, et al. 1,25dihydroxyvitamin D deficiency predicts poorer outcome after renal transplantation. Transpl Proc. 2009;41:3002-5. https://doi. org/10.1016/j.transproceed.2009.07.087.

33. Zittermann A, Schleithoff SS, Gotting C, Fuchs U, Kuhn J, Kleesiek K, et al. Calcitriol deficiency and 1-year mortality in cardiac transplant recipients. Transplantation. 2009;87:118-24. https://doi.org/10.1097/TP.0b013e31818c2708.

34. Zhang A, Zhang M, Wang Y, Xie H, Zheng S. Calcitriol prolongs recipient survival by inducing expression of zinc-finger protein A20 and inhibiting its downstream gene following rat orthotopic liver transplantation. Immunopharmacol Immunotoxicol. 2006;28: 591-600. https://doi.org/10.1080/08923970601067003.

35. Redaelli CA, Wagner M, Tien YH, Mazzucchelli L, Stahel PF, Schilling MK, et al. 1 alpha,25-Dihydroxycholecalciferol reduces rejection and improves survival in rat liver allografts. Hepatology. 2001;34:926-34. https://doi.org/10.1053/jhep.2001.28705.

36. Falleti E, Bitetto D, Fabris C, Cmet S, Fornasiere E, Cussigh A, et al. Association between vitamin D receptor genetic polymorphisms and acute cellular rejection in liver-transplanted patients. Transpl Int. 2012;25:314-22. https://doi.org/10.1111/j.1432-2277. 2011.01419.x.

37. Oblak M, Mlinsek G, Kandus A, Buturovic-Ponikvar J, Arnol M. Paricalcitol versus placebo for reduction of proteinuria in kidney transplant recipients: a double-blind, randomized controlled trial. Transpl Int. 2018;31:1391-404. https://doi.org/10.1111/tri.13323.

38. Kreutz M, Andreesen R, Krause SW, Szabo A, Ritz E, Reichel H. 1,25-dihydroxyvitamin D3 production and vitamin D3 receptor expression are developmentally regulated during differentiation of human monocytes into macrophages. Blood. 1993;82:1300-7.

39. Hall AC, Juckett MB. The role of vitamin D in hematologic disease and stem cell transplantation. Nutrients. 2013;5:2206-21. https://doi.org/10.3390/nu5062206. 
40. Turcotte LM, Cao Q, Cooley SA, Curtsinger J, Holtan SG, Luo X et al. Monocyte subpopulation recovery as predictors of hematopoietic cell transplantation outcomes. Biol Blood Marrow Transplant. 2019. https://doi.org/10.1016/j.bbmt.2019.01.003.

41. DeCook LJ, Thoma M, Huneke T, Johnson ND, Wiegand RA, Patnaik MM, et al. Impact of lymphocyte and monocyte recovery on the outcomes of allogeneic hematopoietic SCT with fludarabine and melphalan conditioning. Bone Marrow Transpl. 2013;48:708-14. https://doi.org/10.1038/bmt.2012.211.

42. Dhakal B, Brazauskas R, Lara CA, Hari P, Pasquini M, D’Souza A. Monocyte recovery at day 100 is associated with improved survival in multiple myeloma patients who undergo allogeneic hematopoietic cell transplantation. Bone Marrow Transpl. 2016; 51:297-9. https://doi.org/10.1038/bmt.2015.244.

43. Hewison M, Freeman L, Hughes SV, Evans KN, Bland R, Eliopoulos AG, et al. Differential regulation of vitamin D receptor and its ligand in human monocyte-derived dendritic cells. J Immunol. 2003;170:5382-90.

44. Adorini L. Immunomodulatory effects of vitamin D receptor ligands in autoimmune diseases. Int Immunopharmacol. 2002;2:1017-28.

45. Bock G, Prietl B, Mader JK, Holler E, Wolf M, Pilz S, et al. The effect of vitamin D supplementation on peripheral regulatory
$\mathrm{T}$ cells and beta cell function in healthy humans: a randomized controlled trial. Diabetes Metab Res Rev. 2011;27:942-5. https://doi.org/10.1002/dmrr.1276.

46. Nalle SC, Turner JR. Intestinal barrier loss as a critical pathogenic link between inflammatory bowel disease and graft-versus-host disease. Mucosal Immunol. 2015;8:720-30. https://doi.org/10.1038/ mi.2015.40.

47. Staffas A, Burgos da Silva M, van den Brink, Marcel RM. The intestinal microbiota in allogeneic hematopoietic cell transplant and graft-versus-host disease. Blood. 2017;129:927-33. https://doi.org/10.1182/blood-2016-09-691394.

48. Wang J, Thingholm LB, Skieceviciene J, Rausch P, Kummen M, Hov JR, et al. Genome-wide association analysis identifies variation in vitamin $\mathrm{D}$ receptor and other host factors influencing the gut microbiota. Nat Genet. 2016;48:1396-406. https://doi.org/10. 1038/ng.3695.

49. Clark A, Mach N. Role of vitamin D in the hygiene hypothesis: the interplay between vitamin $\mathrm{D}$, vitamin $\mathrm{D}$ receptors, gut microbiota, and immune response. Front Immunol. 2016;7:627. https://doi.org/ 10.3389/fimmu.2016.00627.

50. Gratwohl A. The EBMT risk score. Bone Marrow Transpl. 2012;47:749-56. https://doi.org/10.1038/bmt.2011.110. 